\title{
Reduction of chronic non-specific low back pain: A randomised controlled clinical trial on acupuncture and baclofen
}

\author{
Jalal Zaringhalam*, Homa Manaheji, Ali Rastqar and Maryam Zaringhalam
}

\begin{abstract}
Background: Chronic non-specific low back pain (LBP) is a prevalent (80\%) and multi-dimensional illness. This study aims to test whether acupuncture, baclofen, or combined treatment with acupuncture and baclofen alleviates symptoms of non-specific chronic LBP in men.

Methods: Eight-four (84) men aged 50-60 years with non-specific chronic LBP were randomly assigned to four groups: the baclofen group received only baclofen ( $30 \mathrm{mg} /$ day); the acupuncture group received only acupuncture at selected acupoints; the acupuncture + baclofen group received combined treatment with acupuncture and baclofen treatments; and the control group received no pain reduction treatment. After five weeks of treatment, visual analogue scale (VAS) and self-reported pain disability with the Roland-Morris Disability Questionnaire (RDQ) were conducted for outcome measures.

Results: After treatment, the baclofen, acupuncture and acupuncture + baclofen groups all had lower VAS and RDQ scores. Significantly higher reduction and improvement in VAS and RDQ scores were found in the acupuncture and acupuncture + baclofen groups compared to the baclofen group.

Conclusion: The present study indicates that the combined treatment of acupuncture and baclofen is more effective than baclofen treatment alone to reduce pain in patients with non-specific chronic LBP.
\end{abstract}

Trial registration number: ACTRN12609000698279

\section{Background}

Low back pain (LBP) may be the most prevalent illness, with $80 \%$ of the population experiencing it at least once in their lifetime [1]. Up to $90 \%$ of all patients with acute LBP recover quickly with or without treatment $[2,3]$. Ten to forty percent of all LBP cases become chronic which is a burden on the society $[4,5]$. Furthermore, LBP is a multidimensional problem [6] involving pathoanatomical, neurophysiological, physical and psychosocial factors [7]. Most LBP cases are non-specific as definitive diagnosis cannot be established with current radiological methods [4]. The results of research on the effectiveness of treatments for non-specific chronic LBP are inconsistent $[8,9]$.

* Correspondence: jzaringhalam@yahoo.com

1 Physiology Department, Neuroscience Research Centre, Shahid Beheshti University of Medical Sciences, Tehran, Iran

Full list of author information is available at the end of the article
Some studies suggest that the classification of chronic LBP disorders should be homogenous so that specific interventions tailored for these homogenous groups can be more effective [9]. The most common medications for non-specific LBP are skeletal muscle relaxants and opioid analgesics $[8,10]$. Muscle relaxants are used to reduce pain of patients with non-specific LBP and, in particular, non-benzodiazepine muscle relaxants such as baclofen are used for symptomatic treatment of chronic LBP $[8,11]$. Some researchers found that muscle relaxants including baclofen are ineffective [9]. Thus, the use of muscle relaxants for LBP remains controversial. When these drugs are not adequate, another kind of therapy, e.g. acupuncture, is often sought $[12,13]$. Acupuncture stimulates specific points on the body surface with fine needles [14] and relieves pain in chronic LBP patients as accepted by the World Health Organization (WHO) [15]. Acu- 
puncture treatment may improve the disability of patients with LBP $[13,16]$. While acupuncture is widely used by patients with chronic LBP, its effectiveness in pain reduction still lacks evidence $[12,17,18]$. A couple of randomised controlled trials found that combined treatment with acupuncture and baclofen were effective in pain reduction $[11,18]$; however, the efficacy of this combination has not been demonstrated for non-specific chronic LBP. This study aims to test whether acupuncture, baclofen and combined treatment with acupuncture and baclofen can alleviate symptoms of non-specific chronic LBP in men.

\section{Methods}

\section{Participants}

Men aged 50-60 years with non-specific chronic LBP were recruited through local newspapers except for a few patients (eight people) who had contacted the trial research centres of the Tehran University of Medical Sciences (TUMS). Screening of participants was carried out by a qualified musculoskeletal physiotherapist. Participants met all the following inclusion criteria: (1) lumbar or lumbosacral pain for six months or longer; (2) no radiation of low back pain to other regions; (3) normal neurological signs of lumbosacral nerves including deep tendon and plantar reflexes, voluntary motor function, straight leg raise and sensory function; (4) no acupuncture treatment in the past six months; (5) absence of significant pathology such as bone fracture or severe psychiatric conditions; (6) stable health; and (7) all participants experienced ongoing pain, the intensity of which did not change over the course of a day. Patients were excluded if they had any of the following: (1) major trauma or systemic disorders; (2) conflicting or ongoing co-interventions (drugs and/or alternative treatments); (3) prior use of acupuncture for LBP in the past six months; (4) refusal to be randomised; (5) protrusion or prolapse of one or more intervertebral discs with concurrent neurological symptoms; (6) prior vertebral column surgery; (7) infectious spondylopathy; (8) low back pain secondary to an inflammatory, malignant or autoimmune disease; (9) congenital deformation of the spine (except for slight lordosis or scoliosis); or (10) compression fracture caused by osteoporosis, spinal stenosis, spondylolysis or spondylolisthesis [13,19]. At the first appointment, patient characteristics and baseline measurements were recorded. Part of the screening process relied on selfreported information concerning current medical conditions, medications and serious injuries. Before signing a written informed consent, each participant was given an information sheet explaining the nature of the study. This study was approved by the Ethics Committee of the TUMS.

\section{Treatments}

Based on the information of our planned sample size in previous studies [18] and according to the need for adequate statistical power, a sample size of 84 participants (21 per group) was considered both appropriate and feasible. Participants were randomly assigned to four groups: control (C), acupuncture (AC), baclofen (BA) and baclofen plus acupuncture $(B A+A C)$. Participants were randomised with a stratified blocked randomisation scheme (with random block size of four) and statistical software for randomization (Sample Size version 2.0, Intelligent Masters Company, USA). Block randomization design of 4 (i.e. for every 4 subjects recruited, 1 was assigned in AC group, 1 was assigned in the $\mathrm{BA}, 1$ was assigned in $\mathrm{BA}+\mathrm{AC}$ group, and 1 was assigned in the $\mathrm{C}$ group), was used to ensure balance of the numbers in each group. Stratification was also done based on the initial characteristics shown in Table 1 (VAS and RDQ scores). Participants' assignments were concealed in sealed opaque envelopes that were opened by the acupuncturist before treatment. No assignment was reused with another patient once the envelope had been opened.

Treatment course for all groups was five weeks, i.e. standard for chronic pain treatment $[19,20]$. Control group did not receive any treatment for chronic pain. All participants were advised to maintain their normal lifestyle and not to start any new medications. Acupuncture reporting followed the STandards for Reporting Interventions in Clinical Trial of Acupuncture (STRICTA) [14]. Participants in the $\mathrm{AC}$ and $\mathrm{BA}+\mathrm{AC}$ groups received acupuncture treatment performed by a certified acupuncturist twice a week for five weeks. Acupuncture protocol used in this study was consistent with the neurohumoral mechanism theory of acupuncture [21]. Each patient received needles bilaterally in the following acupoints: Shenshu (BL23), Dachangshu (BL25), Panguanshu (BL28), Ciliao (BL32), Kunlun (BL60), Huantiao (GB30) and Yanglingquan (GB34). An aseptic procedure was employed with disposable, stainless 30-gauge needles coupled with electrical stimulation at 4-6 $\mathrm{Hz}$ with pulse duration of $0.5 \mathrm{~ms}$ [22]. Needles $(0.2 \mathrm{~mm} \times 40 \mathrm{~mm}$, Seirin, USA) were inserted into the acupoints until the patient felt dull pain or deqi. At each session 10-12 needles were used bilaterally and needles were left in place for 20-25 minutes. Baclofen was orally administered $30 \mathrm{mg} /$ day $(15$ $\mathrm{mg}$ bid) which is the recommended effective dose for chronic LBP [23] without causing motor impairment [23]. Patients in the BA+AC group received both baclofen (30 $\mathrm{mg} /$ day) and acupuncture for five weeks.

\section{Outcome measures}

Primary outcomes were pain intensity quantified with a $10 \mathrm{~cm}$ visual analogue scale (VAS, $0-100 \mathrm{~mm}$ ) [24] and self-reported pain disability assessed with an Iranian ver- 
Table 1: Baseline participant characteristics

\begin{tabular}{|c|c|c|c|c|c|c|c|c|c|}
\hline \multirow[t]{2}{*}{ Group } & \multirow{2}{*}{$\begin{array}{l}\text { Number of } \\
\text { participant }\end{array}$} & \multirow[t]{2}{*}{ Age } & \multicolumn{3}{|c|}{ Education } & \multirow{2}{*}{$\begin{array}{c}\text { Pain } \\
\text { duration } \\
\text { (years) }\end{array}$} & \multirow[t]{2}{*}{ BMI } & \multirow{2}{*}{$\begin{array}{l}\text { Base RDQ } \\
\text { score }\end{array}$} & \multirow{2}{*}{$\begin{array}{c}\text { Base VAS } \\
\text { score }\end{array}$} \\
\hline & & & $\begin{array}{c}\text { High } \\
\text { school or } \\
\text { less }\end{array}$ & $\begin{array}{l}\text { Technical } \\
\text { school }\end{array}$ & $\begin{array}{l}\text { College } \\
\text { graduate }\end{array}$ & & & & \\
\hline$C$ & 20 & $54.3(4.2)$ & 12 & 2 & 6 & 7 & $31(3.5)$ & $9.7(4.4)$ & 64.5 (19.3) \\
\hline BA & 20 & $55.1(3.3)$ & 13 & 2 & 5 & 6.7 & $29.2(4.2)$ & $9.8(4.2)$ & $64.5(18.3)$ \\
\hline$A C$ & 20 & $54.2(5.4)$ & 12 & 3 & 5 & 7.1 & 32.5 & $9.6(3.9)$ & $64.3(17.8)$ \\
\hline$B A+A C$ & 20 & $54.2(5.6)$ & 13 & 1 & 6 & 6.9 & $30.3(4.1)$ & $9.5(2.8)$ & $64.6(16.8)$ \\
\hline$P$-value & & $>0.7$ & & $>0.05$ & & $>0.4$ & $>0.3$ & $>0.5$ & $>0.5$ \\
\hline
\end{tabular}

Data are presented as mean (SD).

BMI: body mass index

sion of the Roland Morris Questionnaire (RDQ, 0-24 points) which is a reliable and valid instrument for measuring functional status in Persian-speaking patients with LBP $[25,26]$. VAS scores were measured immediately before the first treatment and subsequently at one, two, three, four, five and ten weeks after the first treatment. RDQ scores were measured immediately before the first treatment and subsequently at five and ten weeks after the first treatment. Each VAS or RDQ score was measured immediately before treatment at the specified week $[19,27]$. The concept of the minimal clinically important difference (MCID) [28], helped interpret changes in VAS and RDQ scores at the individual level. If available, MCID in these outcome measures were defined as a 2-point reduction on VAS and 2.5 points reduction on RDQ.

\section{Statistical analysis}

Data are presented as mean (SD). Statistica software (version 6.0, StatSoft, USA) was used in all statistical analyses. One-way analysis of variance (ANOVA) was performed followed by post-hoc Tukey's multiple comparison test (Statistica version 6.0) to determine significant differences in VAS and RDQ scores between groups. Independent $\mathrm{t}$-test was used for comparison of VAS or RDQ scores between two different groups. Statistical significance level was set at $P<0.05$.

\section{Results}

Participants

Participants were recruited between May 2006 and February 2008. Of the 125 respondents, 84 (67.2\%) met the inclusion criteria for participants. Four participants dropped out from the trial during the treatment due to lack of time $(n=2)$ and pain from acupuncture $(n=2)$. Follow-up measurements and analyses were performed on the remaining 80 participants who completed the study (Figure 1). There was no significant difference in baseline variables such as age, disease, VAS and RDQ scores between groups (Table 1).

\section{Changes in VAS scores for pain intensity}

VAS scores for pain intensity decreased significantly in all treatment groups; however, the exact time course varied (Table 2). The BA group showed a significant decrease in VAS at one and two weeks of treatment compared to baseline $(P<0.001)$ and the control group $(P=0.008)$. Baclofen was more effective in pain reduction in the first week of treatment than in the second week $(P=0.04)$. VAS analysis in the BA group found no significant difference between baselines, three, four, five and ten weeks of treatment. Acupuncture significantly decreased the pain intensity after five weeks of treatment and this effect was stable up to the tenth week of the study. VAS demonstrated a significant decrease at the first week after treatment compared to baseline and control group $(P=0.009)$. VAS in the AC group decreased significantly at two, three, four and five weeks compared to baseline $(P<$ $0.001)$ and one week of treatment $(P=0.02)$. Moreover, acupuncture reduced pain intensity more than baclofen at two, three, four and ten weeks of treatment. The $\mathrm{BA}+\mathrm{AC}$ group showed a significant reduction in VAS at all time points of this study $(P<0.001)$. VAS scores were significantly lower in the $\mathrm{BA}+\mathrm{AC}$ group than those in the AC group $(P=0.04)$ (Figure 2).

\section{Changes in RDQ scores for pain disability}

While the interventions decreased RDQ scores in all groups, the exact time course varied (Table 3). Baclofen administration significantly decreased the RDQ scores after five weeks of treatment compared to zero $(P=0.04)$ 

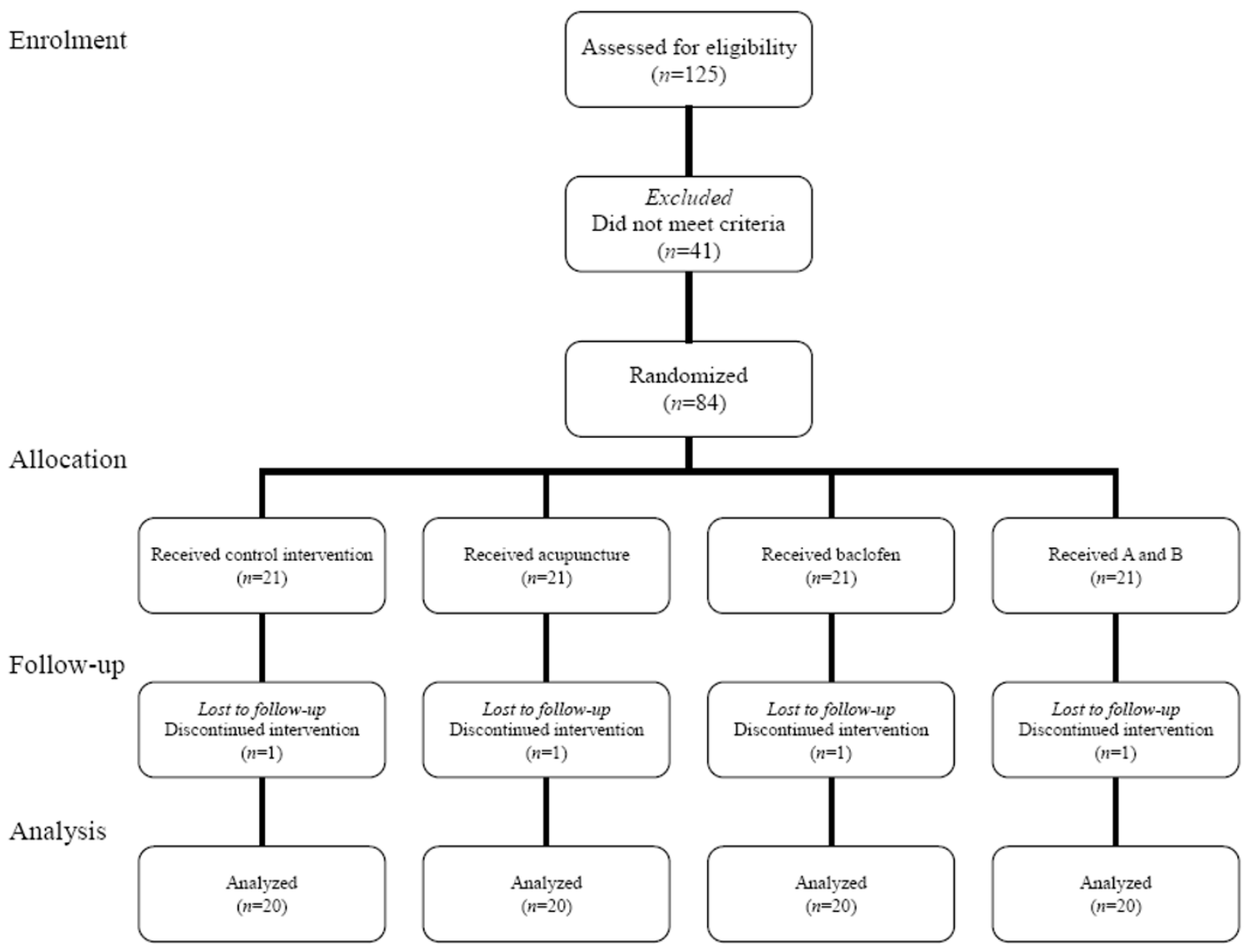

Figure 1 Participants flow in the study.

and ten weeks $(P=0.04)$. RDQ scores in the AC and $\mathrm{BA}+\mathrm{AC}$ groups significantly decreased at both five and ten weeks compared to baseline $(P<0.001)$. There were significant decreases in RDQ scores in the $\mathrm{AC}$ and $\mathrm{BA}+\mathrm{AC}$ groups compared to the $\mathrm{BA}$ group at five $(P<$ $0.001)$ and ten weeks $(P<0.001)$. RDQ scores in the
$\mathrm{BA}+\mathrm{AC}$ group were also significantly lower than those in the AC group throughout the study $(P=0.04)$ (Figure 3 ).

\section{Discussion}

The $\mathrm{AC}$ and $\mathrm{BA}+\mathrm{AC}$ treatments for non-specific chronic LBP were more effective in pain reduction than baclofen

Table 2: Pain intensity scores (VAS) in experimental groups

\begin{tabular}{|c|c|c|c|c|c|c|c|}
\hline \multirow{2}{*}{$\begin{array}{l}\text { Group } \\
(n=20)\end{array}$} & \multicolumn{7}{|c|}{ Weeks } \\
\hline & 0 & 1 & 2 & 3 & 4 & 5 & 10 \\
\hline $\mathrm{C}$ & $64.5(19.3)$ & $64.2(21.1)$ & $64.1(19.4)$ & $64.1(22.3)$ & $64.3(20.1)$ & $64.3(23.8)$ & $64.2(25.5)$ \\
\hline BA & $64.5(18.3)$ & $52.8(19.4) \#$ & $55.1(21.1)$ & $62.1(18.7)$ & $63(20.2)$ & $61.9(22.3)$ & $63.7(24.4)$ \\
\hline$A C$ & $64.3(17.8)$ & $56.5(19.9)$ & 50.5 (20.1)\# & $\begin{array}{l}49.1 \\
(19.3) \# \# \#\end{array}$ & $\begin{array}{l}47.3 \\
(18.9) \# \# \#\end{array}$ & 47 (19.1)\#\#\# & $\begin{array}{l}50.1 \\
(20.3) \# \# \#\end{array}$ \\
\hline $\mathrm{BA}+\mathrm{AC}$ & $64.6(16.8)$ & $52.1(15.9) \neq$ & $45.1(15.2) \neq$ & $45.6(14.7) \neq$ & 42.3 (13.9)‡ & $40.1(13.3) \neq$ & 47.3 (14.1)‡ \\
\hline
\end{tabular}




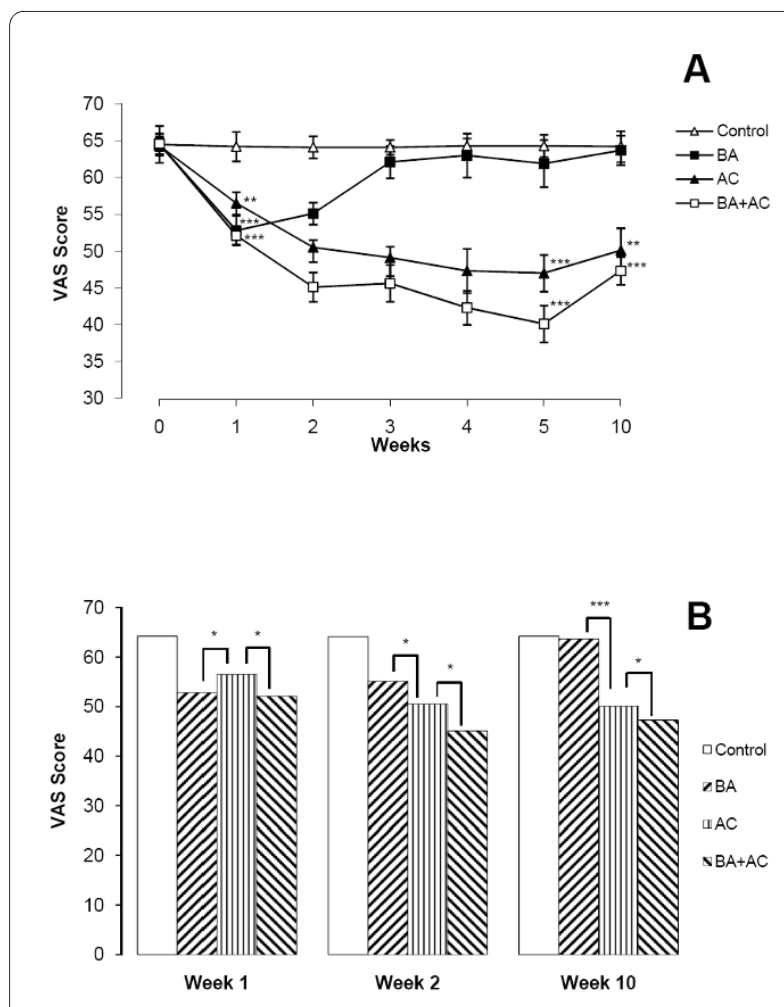

Figure 2 VAS scores for pain intensity. (A) Comparison between control and $\mathrm{AC}, \mathrm{BA}$ or $\mathrm{BA}+\mathrm{AC}$. (B) Comparison between $\mathrm{AC}, \mathrm{BA}$ and $B A+A C .{ }^{*} P<0.05 .{ }^{* *} P<0.01 .{ }^{* *} P<0.001$.

treatment alone. Moreover, the anti-nociceptive effects in the $\mathrm{AC}$ and $\mathrm{BA}+\mathrm{AC}$ groups were also more persistent at follow-ups. Acupuncture has demonstrated its potential as a promising treatment for chronic LBP $[29,30]$. While a number of theories of how acupuncture may treat LBP are available, no accepted mechanism has emerged $[30,31]$. Similar to descending inhibitory and/or diffuse noxious inhibitory controls in the central nervous system, acupuncture may stimulate the small-diameter afferent fibres, which then reduce the transmission of pain signals thereby inhibiting pain discrimination and perception

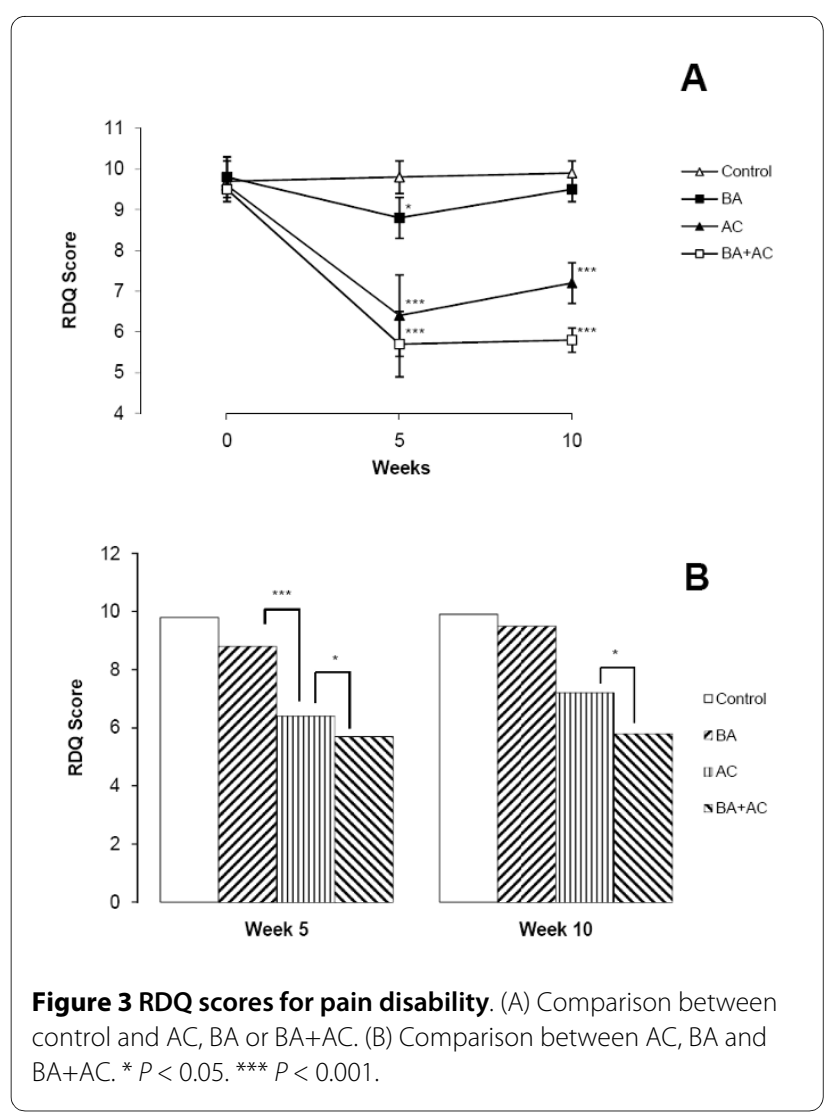

[32]. Low back muscle spasm and muscle blood flow decrease are the main underlying causes of chronic LBP [33]. Acupuncture alleviates tension and improves blood flow in the treated muscles [34]. Thus, acupuncture treatment may improve lumbar function and reduce pain via increasing the blood flow to the affected region [35]. Non-benzodiazepine muscle relaxants are often used to treat non-specific LBP [36], as a gamma-aminobutyric acid (GABA) derivative with central nervous system action and a substance $P$ antagonist $[37,38]$. In this study baclofen $(30 \mathrm{mg} /$ day per oral) reduced the pain intensity but only effective in the first two weeks. These results are

Table 3: Ronald Morris Questionnaire (RDQ) scores in experimental groups

\begin{tabular}{|c|c|c|c|}
\hline \multirow{2}{*}{$(n=20)$ Group } & \multicolumn{3}{|c|}{ Week } \\
\hline & 0 & 5 & 10 \\
\hline C & $9.7(4.4)$ & $9.8(3.9)$ & $9.9(4.6)$ \\
\hline BA & $9.8(4.2)$ & $8.8(3.8)$ & $9.5(4.1)$ \\
\hline$A C$ & $9.6(3.9)$ & 6.4 (2.9)‡ & $7.2(3.1) \neq$ \\
\hline $\mathrm{BA}+\mathrm{AC}$ & $9.5(2.8)$ & 5.7 (1.4)\#\#\# & 5.8\#\#\# \\
\hline
\end{tabular}

Data are presented as mean (SD).

$\neq P<0.05$ : comparing $\mathrm{AC}$ with $\mathrm{BA}+\mathrm{AC}$

$\# \#$ \# $<0.001$ : comparing $\mathrm{BA}+\mathrm{AC}$ with $\mathrm{BA}$ 
in line with a previous study that did not find significant and consistent decrease in pain intensity with baclofen treatment for chronic spastic pain [39]. Due to the controversies some practitioners are reluctant to prescribe baclofen to their patients [9]. Baclofen is effective for immediate pain relief [24], whereas acupuncture is effective to treat long-term pain and alleviate pain-related disabilities $[27,40,41]$. As baclofen treatment alone does not produce major functional benefits [42], combination treatment maybe an alternative [43]. This RCT does show that the BA+AC group had lower VAS and RDQ scores than other groups, i.e., the combined acupuncture and baclofen treatment is more effective to treat non- specific chronic LBP than either treatment alone [44].

\section{Conclusion}

The present study indicates that the combined treatment of acupuncture and baclofen is more effective than baclofen treatment alone to reduce pain in patients with non-specific chronic LBP.

\section{Abbreviations}

LBP: Low back pain; VAS: Visual analogue scale; RDQ: Roland-Morris Disability Questionnaire; NSAIDs: Non-steroidal anti-inflammatory drugs; WHO: World Health Organization; TUMS: Tehran University of Medical Sciences; C: Control; AC: Acupuncture; BA: Baclofen; BA+AC: Baclofen plus acupuncture; STRICTA: STandards for Reporting Interventions in Clinical Trial of Acupuncture; BL: Bladder; GB: Gallbladder; SD: Standard deviation; MCID: Minimal clinically important difference; ANOVA: One-way analysis of variance; GABA: Gamma-aminobutyric acid; RCT: Randomised controlled trial.
\end{abstract}

\section{Competing interests}

The authors declare that they have no competing interests.

\section{Authors' contributions}

JZ designed the study, performed the acupuncture treatment and drafted the manuscript. HM conceived the study and participated in the sequence alignment of the study. AR designed the study and performed the statistical analysis. MZ coordinated the study. All authors read and approved the final version of the manuscript.

\section{Acknowledgements}

The authors are grateful to the Tehran University of Medical Sciences and the Neuroscience Research Centre of the Shahid Beheshti University of Medical Sciences for their assistance in study design.

\section{Author Details}

Physiology Department, Neuroscience Research Centre, Shahid Beheshti University of Medical Sciences, Tehran, Iran

Received: 1 November 2009 Accepted: 24 April 2010

Published: 24 April 2010

\section{References}

1. Kelsey JL, White AA: Epidemiology and impact of low back pain. Spine 1980, 5(2):133-139.

2. Deyo RA, Weinstein JN: Low back pain. N Engl J Med 2001, 344:363-370.

3. Waddell G: The Backpain Revolution Edinburgh: Churchill Livingstone; 2004.

4. Dillingham T: Evaluation and management of low back pain: and overview. State Art Rev 1995, 9(3):559-74.

5. Croft PR, Macfarlane GJ, Papageorgiou AC, Thomas E, Silman AJ: Outcome of low back pain in general practice: a prospective study. BMJ 1998 316:1356-1359.
6. Borkan J, van Tulder M, Reis S, Schoene ML, Croft P, Hermoni D: Advances in the field of low back pain in primary care: a report from the fourth international forum. Spine 2002, 27(5):E128-132.

7. McCarthy C, Arnall F, Strimpakos N, Freemont A, Oldham J: The biopsychosocial classification of non-specific low back pain: a systematic review. Phys Ther Rev 2004, 9(1):17-30.

8. Chou R, Huffman LH: Medications for acute and chronic low back pain: a review of the evidence for an American Pain Society/American College of Physicians clinical practice guideline. Ann intern med 2007, 147(7):505-514.

9. van Tulder MW, Koes BW, Bouter LM: Conservative treatment of acute and chronic nonspecific low back pain. A systematic review of randomized controlled trials of the most common interventions. Spine 1997, 22(18):2128-2156

10. Eisenberg DM, Davis RB, Ettner SL, Appel S, Wilkey S, van Rompay M, Kessler RC: Trends in alternative medicine use in the United States, 1990-1997: results of a follow-up national survey. JAMA 1998, 280(18):1569-1575.

11. van Tulder MW, Touray T, Furlan AD, Solway S, Bouter LM: Muscle relaxants for nonspecific low back pain: a systematic review within the framework of the cochrane collaboration. Spine 2003, 28(17):1978-1992.

12. Chou R, Huffman LH: Nonpharmacologic therapies for acute and chronic low back pain: a review of the evidence for an American Pain Society/American College of Physicians clinical practice guideline. Ann Intern Med 2007, 147(7):492-504.

13. Ernst $E$, White AR: Acupuncture for back pain: a meta-analysis of randomized controlled trials. Arch Intern Med 1998, 158(20):2235-2241.

14. MacPherson H, White A, Cummings M, Jobst KA, Rose K, Niemtzow R: Standards for reporting interventions in controlled trials of acupuncture: the STRICTA recommendations. Complement Ther Med 2001, 9(4):246-249.

15. WHO acupuncture research [http://apps.who.int/medicinedocs/en/d/ Js4926e/

16. Eshkavari L: Acupuncture and pain: a review of the literature. AANAJ 2003, 71(5):361-370.

17. Manheimer E, White A, Berman B, Forys K, Ernst E: Meta-analysis: acupuncture for low back pain. Ann Intern Med 2005, 142(8):651-663.

18. Itoh K, Itoh S, Katsumi Y, Kitakoji H: A pilot study on using acupuncture and transcutaneous electrical nerve stimulation to treat chronic nonspecific low back pain. Complement Ther Clin Pract 2009, 15(1):22-25.

19. Helms JM: An overview of medical acupuncture. Altern Ther 1998, 4(3):35-45.

20. Frymoyer JW: Back pain and sciatica. N Eng/ J Med 1988, 318:291-300.

21. Cheng X: Chinese Acupuncture and Moxibustion Beijing: Foreign Language Press; 1999

22. Stux G, Pomeranz B: Acupuncture: a textbook and atlas Berlin: SpringerVerlag; 1987.

23. Dapas F, Hartman SF, Martinez L, Northrup BE, Nussdorf RT, Silberman $H M$, Gross $\mathrm{H}$ : Baclofen for the treatment of acute low-back syndrome. A double-blind comparison with placebo. Spine 1985, 10(4):345-349.

24. Deyo R: Comparative validity of the sickness impact profile and shorter scales for functional assessment in low-back pain. Spine 1986, 11(9):951-954

25. Mousavi SJ, Parnianpour M, Mehdian H, Montazeri A, Mobini B: The Oswestry Disability Index, the Roland-Morris Disability Questionnaire, and the Quebec Back Pain Disability Scale: translation and validation studies of the Iranian versions. Spine 2006, 31(14):E454-E459.

26. Patrick DL, Deyo RA, Atlas SJ, Singer DE, Chapin A, Keller RB: Assessing health-related quality of life in patients with sciatica. Spine 1995, 20(17):1899-1908.

27. Weiner DK, Perera S, Rudy TE, Glick RM, Shenoy S, Delitto A: Efficacy of percutaneous electrical nerve stimulation and therapeutic exercise for older adults with chronic low back pain: A randomized controlled trial. Pain 2008, 140(2):344-357.

28. Yuan J, Purepong N, Hunter RF, Kerr DP, Park J, Bradbury I, McDonough S: Different frequencies of acupuncture treatment for chronic low back pain: An assessor-blinded pilot randomised controlled trial. Complement Ther Med 2009, 17(3):131-140.

29. Brinkhaus B, Witt CM, Jena S, Linde K, Streng A, Wagenpfeil S, Irnich D, Walther HU, Melchart D, Willich SN: Acupuncture in patients with 
chronic low back pain, a randomized controlled trial. Arch Intern Med 2006, 166(4):450-457.

30. Molsberger AF, Zhou J, Arndt D, Teske W: Chinese Acupuncture for Chronic Low Back: An International Expert Survey. J Altern Complement Med 2008, 14(9):1089-1095.

31. Koes BW, Assendelft WJJ, Heijden GJMG van der, Bouter LM: Spinal manipulation for low back pain. An updated systematic review of randomized controlled clinical trials. Spine 1996, 21(24):2860-2871.

32. Kawakita K, Gotoh K: Role of polymodal receptors in the acupuncturemediated endogenous pain inhibitory systems. Prog Brain Res 1996, 113:507-523.

33. Johnson EW: The myth of skeletal muscle spasm. Am J Phys Med Rehabil 1989, 68(1):1

34. Kawakita K: Polymodal receptor hypothesis on the peripheral mechanisms of acupuncture and moxibustion. Am J Acupunct 1993, 21(4):331-338.

35. Leibing E, Leonhardt U, Koster G, Goerlitz A, Rosenfeldt JA, Hilgers R, Ramadori G: Acupuncture treatment of chronic low-back pain - a randomised, blinded, placebo-controlled trial with nine-month followup. Pain 2002, 96(1-2):189-96.

36. Cherkin DC, Wheeler KJ, Barlow W, Deyo RA: Medication use for low back pain in primary care. Spine 1998, 23(5):607-14

37. Herman RM, D'Luzansky SC, Ippolito R: Intrathecal baclofen suppresses central pain in patients with spinal lesions. A pilot study. Clin J Pain 1992, 8(4):338-345.

38. Abbruzzese G: The medical management of spasticity. Eur J Neurol 2002, 9(s1):30-34.

39. Loubser PG, Akman NM: Effects of intrathecal baclofen on chronic spinal cord injury pain. J Pain Symptom Manage 1996, 12(4):241-247.

40. Chan CWY, Tsang H: Inhibition of the human flexion reflex by low intensity, high frequency transcutaneous electrical stimulation (TENS) has a gradual onset and offset. Pain 1987, 28(2):239-253.

41. Kumazawa T: Nociceptors and autonomic nervous control. Asian Med J 1981, 24:632-656

42. Zheng Z, Guo RJ, Helme RD, Muir A, Costa CD, Xue CL: The effect of electroacupuncture on opioid-like medication consumption by chronic pain patients: A pilot randomized controlled clinical trial. EURJ Pain 2008, 12(5):671-676.

43. Itoh K, Hirota S, Katsumi Y, Ochi H, Kitakoji H: A pilot study on using acupuncture and transcutaneous electrical nerve stimulation to treat knee osteoarthritis (OA). Chin Med 2008, 3:2.

44. Moher D, Schulz KF, Altman DG: The CONSORT statement: revised recommendations for improving the quality of reports of parallelgroup randomised trials. Lancet 2001, 357(9263):1191-94.

doi: $10.1186 / 1749-8546-5-15$

Cite this article as: Zaringhalam et al., Reduction of chronic non-specific low back pain: A randomised controlled clinical trial on acupuncture and baclofen Chinese Medicine 2010, 5:15

\section{Submit your next manuscript to BioMed Central} and take full advantage of:

- Convenient online submission

- Thorough peer review

- No space constraints or color figure charges

- Immediate publication on acceptance

- Inclusion in PubMed, CAS, Scopus and Google Scholar

- Research which is freely available for redistribution

Submit your manuscript at www.biomedcentral.com/submit
C Biomed Central 